\title{
Marginal accuracy on titanium implant abutments with ring and ringless casting technique- An in vitro study
}

\author{
Himanshu Aeran ${ }^{1, *}$, Lara Jain ${ }^{2}$, Neeraj Sharma ${ }^{3}$, Jyotsna Seth ${ }^{4}$ \\ ${ }^{1}$ Director Principal, Professor \& HOD, ${ }^{2}$ PG Student, ${ }^{3,4}$ Reader, Dept. of Prosthodontics, Seema Dental College and Hospital,
} Rishikesh, Uttrakhand, India

*Corresponding Author:

Email: drhimanu@yahoo.com

\begin{abstract}
Purpose: The ring-less investment system is in use for dental casting, although there was no adequate scientific data to support its use either for conventional fixed dental prosthesis or implant retained fixed dental prosthesis. The purpose of this study was to determine whether the ringless casting and accelerated wax-elimination techniques can be combined to offer a cost-effective, clinically acceptable, and time-saving alternative for fabricating single unit castings in fixed prosthodontics.

Materials and Method: An in-vitro study was undertaken to compare the vertical marginal accuracy of single full coverage metal copings, between ring-less and metal ring investment techniques, using two different investment materials and two different types of casting techniques, conventional and accelerated for implant supported dental prosthesis. Four groups were made of forty samples each. All copings were identical, Microscopic measurements were recorded at 80X magnification on the perpendicular to the axial wall at four predetermined sites. The measurements thus obtained were tabulated and statistically analyzed.

Result and Conclusion: Within the limitation of the study the following conclusions were drawn from the data obtained in this study, Mean Vertical gap was the maximum for Group IV (53.58), followed by Group II (44.27), Group I (44.27) and Group III (36.11), which was statistically significant. Conventional casting using ringless (Group III) coping had shown least vertical marginal discrepancy and statistically significantly better marginal fit than that fabricated by conventional and accelerated casting with metal ring investments. Accelerated casting using ringless (Group IV) coping had shown statistically maximum vertical marginal discrepancy among the four methods. The methods used for accelerated casting technique with using ringless process are technique sensitive. Minor variations in the procedures shown defects such as nodules, fins and porosity. Ring-less system of casting can be recommended for use in fabricating implant supported fixed dental restorations.
\end{abstract}

Keywords: Ringless Casting, Casting, Accelerated Casting, Marginal Fit.

\section{Introduction}

Osseointegration offers new treatment options for the edentulous and partially edentulous

patients, the use of dental implants to support and retain dental prosthesis has been demonstrated to be clinically efficacious. ${ }^{1}$ Although dental implants are clinically well accepted, they may still manifest some mechanical and technical implications.

A Precise fit between the abutment and the framework is indispensable to provide a satisfactory long- term clinically well accepted, they may still manifest some mechanical and technical complications. ${ }^{2}$ for instance, fitting the prosthesis to the supporting components is a bewildering problem ${ }^{1,2}$ and many researchers concerned the fit of the dental prosthesis, reporting the high likelihood of misfit in a dental implant components. ${ }^{3-8}$

The marginal fit has been recognized as a reason in failure of cast restorations. ${ }^{2}$ The association between the ill-fitting margins and bacterial irritation should also be concerned as an impending clinical problem with implant supported restorations. Oral microorganisms penetrate through the restorations. Oral microorganism penetrate through the gaps present in implant supported supra structure and this microbial leakage becomes a definite jeopardy to induce periimplantitis. ${ }^{9-10}$ Beyond these biologic disputes, it has been reported that prosthesis misfit would lead to occlusal imprecision, screw fracture, screw loosening and increasing the possibility of abutment and / or implant failure. ${ }^{2,7,11}$ In fact, marginal misfit transmits high stresses to the alveolar bone and dental implant components., ${ }^{9}, 12,13$

The accuracy of fit is affected by the quality of the preparation (undercut, taper of the preparation), the impression, the working cast, the quality of the wax that is used for the lost wax technique and by the accuracy of the castings. At this last step, it is essential to achieve compensation for the shrinkage of the solidifying alloy by increment expansion. This method of compensation was scientifically studied in the 1920s by wienstien and loleman at the US National Bureau of standards ${ }^{14,15}$ the investment initially used was a gypsum bonded type investment. Today 3 methods of compensation for the metal shrinkage on cooling are in regular use ${ }^{16}(1)$ setting expansion of the investment, (2) Hygroscopic expansion of the investment (3) Thermal expansion of the investment.

Gypsum alone can be heated to temperature as high as 1200degree Celsius without decomposing ${ }^{17-19}$ making it sufficiently heat resistant to be used without adding other refractory materials. However, gypsum at this temperature shrinks noticeably, so silica is added to the investment and compensate for this condition. Silica is usually thought of as the refractory component in an 
investment but reduces the heat resistance of gypsum. ${ }^{14,15,17,20}$ Silica is added to control the dimensional changes when the investment is heated, yet it also reduces the compressive strength and makes the use of metals ring necessary to protect the investment during the casting forces. ${ }^{21,22}$ However, there are some phosphate bonded investments do not show hygroscopic expansion, even when mixed with silica sol. The thermal curves of phosphate - bonded investments show more irregularities than the gypsum bonded investment were treated with the same techniques as used with the gypsum bonded investments was not questioned, because its use was a standard procedure. ${ }^{23,24}$ The use of the casting ring was challenged with the introduction of a ringless technique initially for phosphate- bonded investments for removable partial denture framework and recently, for conventional fixed restoration and even experimentally for implant connected frameworks. ${ }^{25,26}$ The high strength of the materials makes it possible and abandon the use of the casting ring. The ringless techniques are easier, less experience, and give clinically acceptable castings. ${ }^{25}$

Refinement of casting process has evolved through enhancement of impression materials, use of die spacers, improvement in the properties of dental waxes, die materials and investment materials, superior technique that allow more precise control of mold expansion, changes in dental alloy formulation and improved fitting techniques.

Conventional techniques requires minimum 1 hour bench set time for investment followed by burnout procedure before casting and the total processing needs 2-4 hours.

However, in 1998, Marzouk and Kerby proposed an accelerated casting technique and minimizes the time consumed in casting procedure. ${ }^{26}$ The accelerated casting technique has been attempted in an effort to achieve similar quality results in 30-40 minutes which is significantly time-saving. However in the literature there are few studies comparing the conventional ring method with the conventional ringless method and accelerated metal ring investing technique with accelerated ringless investment procedures and their marginal accuracy.

Hence, the purpose of this in vitro study is to comparative evaluation of the marginal accuracy of base metal alloy copings fabricated on titanium implant abutments made with ring and ringless method using conventional and accelerated casting technique.

\section{Materials and Method}

An in-vitro study was undertaken to compare the vertical marginal accuracy of single full coverage metal copings, between ring-less and metal ring investment techniques and two different casting techniques, conventional and accelerated casting technique. Four groups were made of forty samples each Group I consisted of conventional casting procedure with metal ring (pbosphate bonded investment material). Group II consisted of accelerated casting procedure with metal ring (Bella sun. investment material). Group III consisted Conventional casting procedure with ring-less (Bella sun" investment material). Group IV consisted Accelerated casting procedure with ringless investment system (Bella sun" investment material). The wax patterns were prepared on a straight abutment with standard margin $3 \mathrm{~mm}$, Alpha Bio Tec, Israel was mounted on die stone using implant analogue, Alpha Bio Tech, Israel. This mounted die stone have a standard dimensions was $40 \mathrm{~cm} \times 10 \mathrm{~cm}$. (Fig. 1) shape of abutment was a tapered cone having length of $6.5 \mathrm{~mm}$, diameter $4.8 \mathrm{~mm}$ in cervical region and $3.5 \mathrm{~mm}$ occulaslly with 4 degree taper. Orientation guides in the form rectangular mark were prepared on the superior surface of the abutment at specific four points midpalatal, midbuccal, mesial and distal, cast and finished. All copings (samples) seated on the abutment and the accuracy of fit was evaluated by measuring the gap between the margins of the sample at four specific sites using a Binocular Stereo Microscope, LabiovisionKSZ 2000, 80X magnification.

Wax pattern of the shape of a tapered cone with approximate width of $1 \mathrm{~mm}$ was prepared using

Kronenwacbs $^{\circ}$ (BEGO, Bremen, Germany) and remargination was carried out using Cervikalwachs. (BEGO, Bremen, Germany). Wax pattern was then sproed and invested in a metal ring with single layer of wet cellulose acetate ring liner, using carbon free phosphate bonded investment material PCT" FlexVest (Ivoclar Vivadent, Liecbtenstein, Italy). Burnout of the wax pattern and casting was carried out in a conventional manner using burn-out furnace (Unident, Australia) and induction casting machine (Fornex T, Bego, S. No. 1255) respectively. Ni-Cr alloy -WrrnUoy"(BEGO, Breden Germany) was used for casting of metal coping space former. The finished metal coping thus obtained was then kept on the abutment (mounted on die stone block) on which wax pattern was fabricated. Wax patterns with any deficiencies were discarded. Remargination of wax pattern (cervical $1 \mathrm{~mm}$ ) was carried out using pink inlay marginal wax- Cervikalwacbs" (BEGO, Bremen, Germany). 160 patterns were fabricated and divided into 4 groups (Group I, II and III) of 40 patterns each.

Group I included metal ring investment system with single layer of cellulose acetate ring liner and carbon free Phosphate Bonded investment material B.No. 01574: Bellavest T.

Group II was First investment material Bellavest $\mathrm{SH}$, phosphate bonded investment material, BEGO, Germany was mixed according to manufactures instructions. Than the mixed investment material was put into metal ring having a single layer of wet cellulose as a ring liner. After bench set for 13-17 minutes, metal ring was placed inside the burnout furnace, Unident, Australia) preheated at $815^{\circ} \mathrm{c}$ with holding time of 15 minutes. 
GROUP III was first investment material Bellasun, phosphate bonded investment material, BEGO, Germany was mixed according to manufactures instructions. Then the mixed material was put into the ring. After initial set of investment material i.e. approximately after 10 minutes, ring was removed. Than the mould was placed in the burnout furnace, Unident, Australia at room temperature and temperature gradually increases up to $1040^{\circ} \mathrm{C}$ with holding time of 45 minutes.

Group IV was first investment material Bellavest $\mathrm{SH}$, phosphate bonded investment material, BEGO, Germany was mixed according to manufactures instructions. Than the investment material was put into ring. After bench set for 13-17 minutes, mould was removed from ring and placed inside burnout furnace, Unident, Australia preheated at $815^{\circ} \mathrm{c}$ with holding time of 15 minutes.

A preformed sprue wire of $3 \mathrm{~mm}$ diameter and 15 $\mathrm{mm}$ length was used for sproing. The patterns were sprued at the occlusal level of wax pattern at an angle of $45^{\circ}$. A reservoir in the shape of a bead of wax was attached about $5 \mathrm{~mm}$ away from the pattern. The highest point of the pattern was kept $6 \mathrm{~mm}$ below the open end of the casting ring so as to allow escape of gases during burnout stage and prevent fracture of investment due to impact of molten metal during casting process. All sharp junctions were eliminated by suitable addition of casting wax to avoid any turbulence in the molten alloy during the filling of the mould. The sprued patterns were carefully weighed in order to calculate the number of alloy ingots required for casting. Metal rings of size $3 x$ and lined with single layer of asbestos free cellulose acetate liner were used for investing wax patterns of group I and II. For Group III and IV instead of metal ring, a ring-less system - Phosphate bonded B. No. D-28379 investment material: Bellasum $3 \mathrm{x}$ size was used. The sprued pattern was attached to the base former and the casting ring was then placed over it. (Fig. 3)

For Group I and Group II The recommended powder liquid ratio of $100 \mathrm{gm} ; 23 \mathrm{ml}$ was used. The powder and liquid were carefully hand mixed in a clean rubber bowl using clean spatula for 15 seconds until the investment was uniformly moist with no lumps. The mixed investment was first carefully applied to the pattern with a brush and then the investment material was vibrated into the casting ring placed on a bench vibrator till it was filled to the top. The investment rings were allowed to set undisturbed for 60 minutes. For Group III and IV the moulds were removed from the ring after initial setting of investment material. Single wax pattern was invested at a time and processed so as to standardize the thickness of investment surrounding wax patterns. Silicone base former was removed after 60 minutes of set at room temperature. The mould/ring was then placed in burnout furnace. For Group I and Group III The temperature of furnace was gradually increased from room temperature to $27 \mathrm{O}$ degree $\mathrm{C}$ with holding time of 30 minutes, from 270 degree $C$ to 560 degree $C$ with holding time of 20 minutes and from 560 degree $\mathrm{C}$ to final temperature of 1040 degree $\mathrm{C}$ with holding time of 45 minutes at maximum temperature. Nickel-Chromium metal casting alloy (WirolloyB.No. D-28359) was used for casting. The moulds casting rings were allowed to bench cool to room temperature before divesting from the investment. The remaining adherent investment was removed by sandblasting (Novadent, LABO 16) with aluminum oxide followed by steam cleaning using steam cleaner (BEGO Bremen. Germany). The sprue was removed using high speed cut-off discs.

Castings were examined under magnification and proper illumination. Isolated nodules were removed using sintered diamond burs and stones. The castings were finished minimally. The inner surface of the castings was not touched at all. (Fig. 3)

Predetermined four points on abutment were marked as position midbuccal, midpalatal, midmesial and middistal. The casting was seated on the abutment The equipment used for measuring the vertical marginal accuracy was Binocular Stereo Microscope, Labiovision- KSZ 2000 at 80X magnification. (Fig. 4)

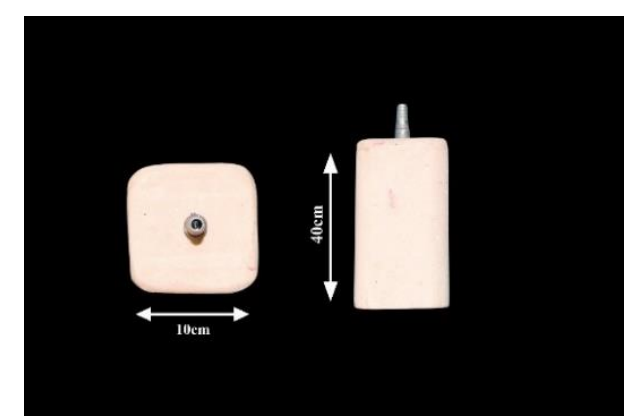

Fig. 1: Preparation of Test Sample

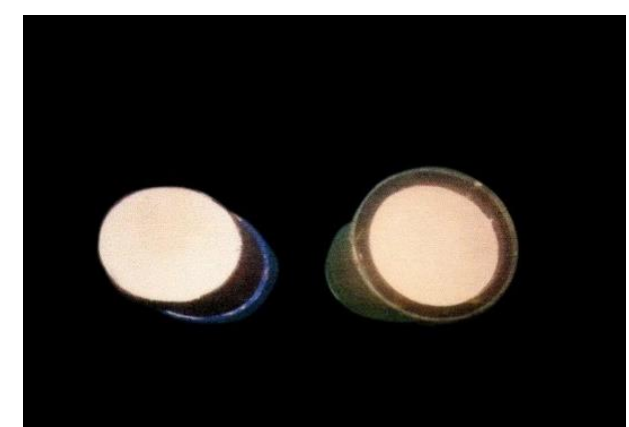

Fig. 2: Investing procedure for the pattern 


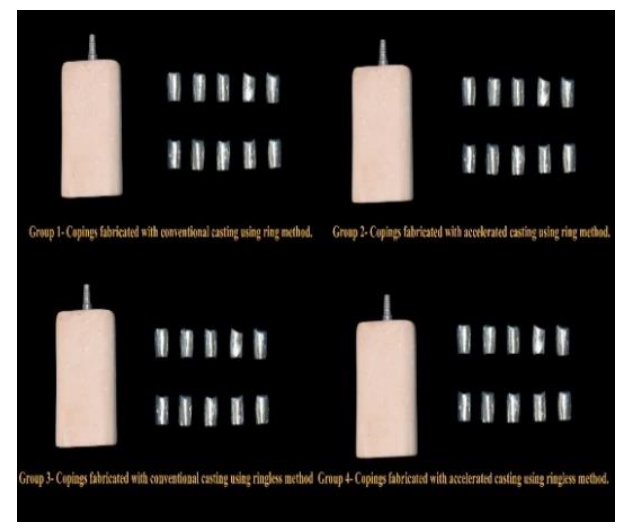

Fig. 3: Fabricated Total Test Samples

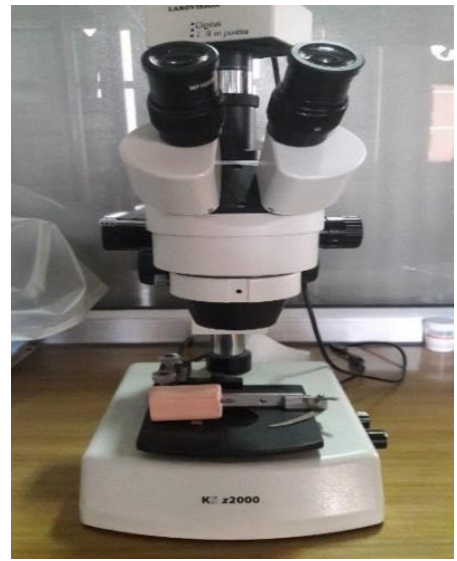

Fig. 4: Measuring dimension of Test samples

\section{Results}

Results obtained were tabulated and subjected to statistical analysis. Graph 1 depicts that, on assessing the fourty samples at 4 points, the maximum mean was found to be of sample no 15 (47.79) and minimum was found to be of sample no. 1 and 32 . This difference is statistically significant with the $\mathrm{p}$ value $<0.05$. Graph 2 depicts that, on assessing the fourty samples at 4points, the maximum mean was found to be of sample no 13 (42.48) and minimum was found to be of sample no.19 (29.99). This difference is statistically highly significant with the $\mathrm{p}$ value $<0.001$. Graph 3 depicts that, on assessing the fourty samples at 4 points, the maximum mean was found to be of sample no 36 (48.84) and minimum was found to be of sample no.1(44.49). This difference is statistically highly significant with the $p$ value <0.001. Graph 4 depicts that, on assessing the fourty samples at 4 points, the maximum mean was found to be of sample no 33, 39, 40 (55.46) and minimum was found to be of sample no.34(50.65). This difference is statistically significant with the $p$ value $<0.05$. Graph 5 shows the mean and standard deviation of group I, II, III, and IV. ANOVA test was conducted to determine the pvalue. The p-value was found to be less than 0.001 which indicates that there is a very high significant difference between the groups. Multiple comparisons were done with Tukey HSD test. There is a statistically significant difference between group 1 and group 2, group 1 and group 3, group 2 and group 3, group 2 and group 4 and group 3 and group 4 . However, differences between group 1 and group 4 were found to be statistically insignificant.

Graph 1: Basic data of vertical marginal gap for group I test samples

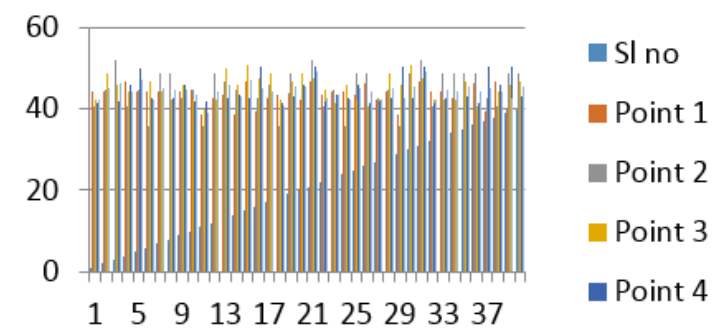

Graph 2: Basic data of vertical marginal gap for group II test samples

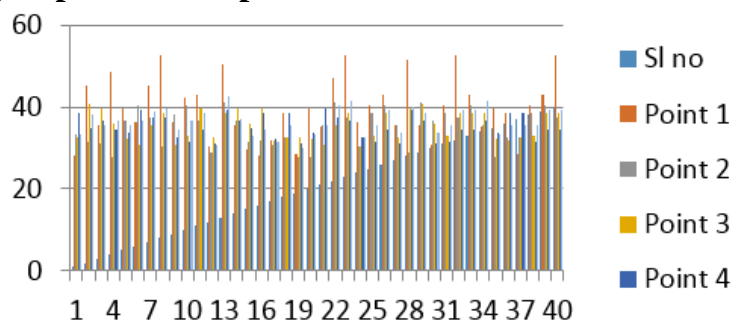

Graph 3: Basic data of vertical marginal gap for group III test samples

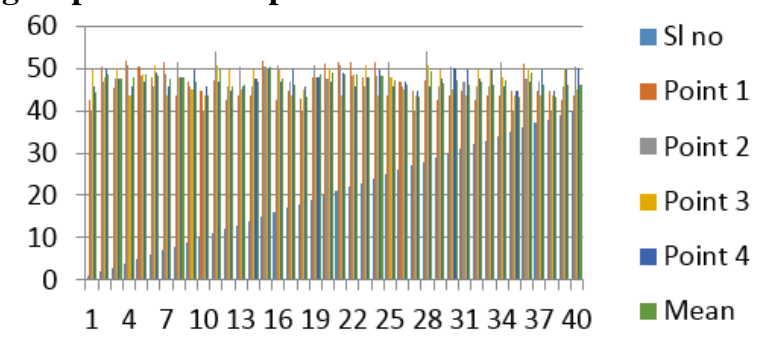

Graph 4: Basic data of vertical marginal gap for group IV test samples

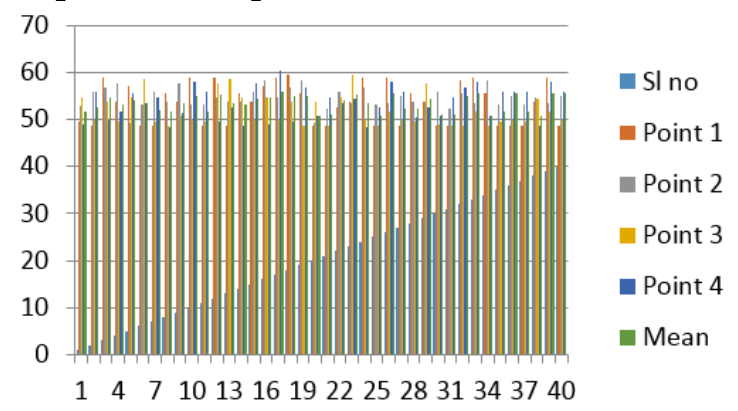


Graph 5: Descriptive statistics formean vertical marginal gap for group I, II, III and IV
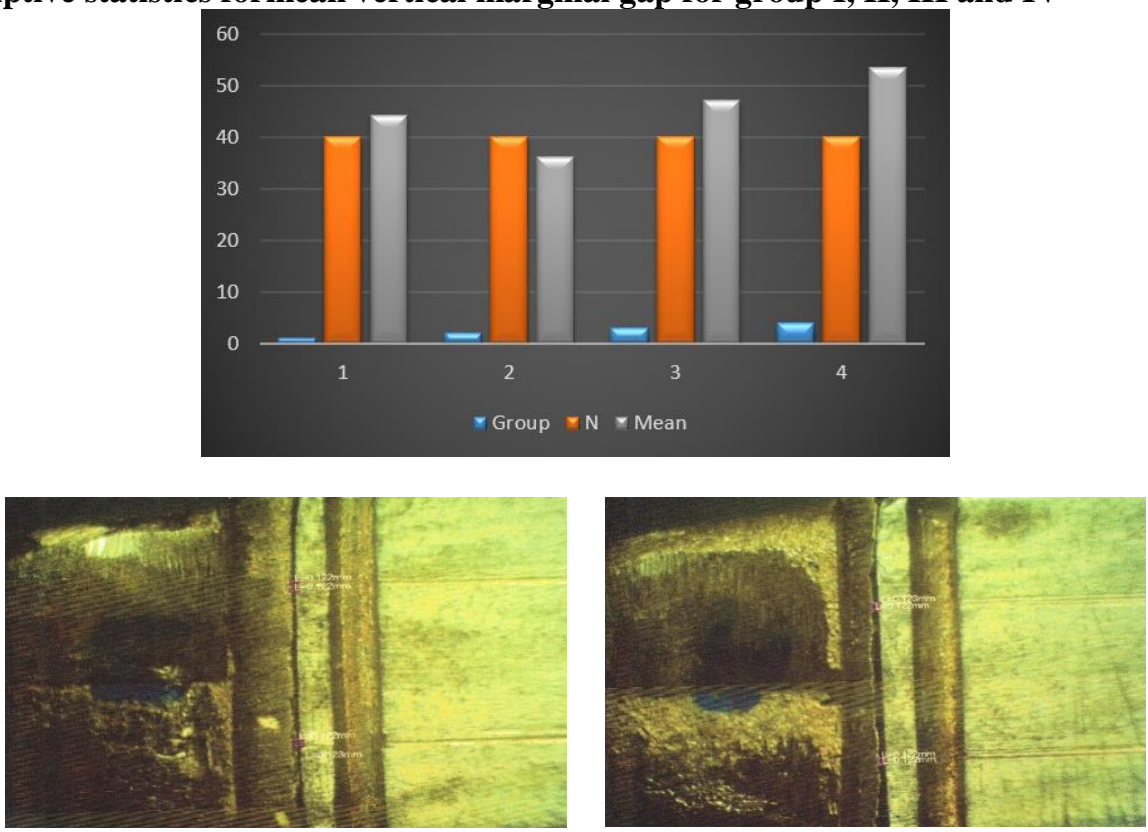

Fig. 5 \& 6: Microscopic view of coping fabricated with conventional casting technique using metal ring method showing marginal discrepancies (Group 1)
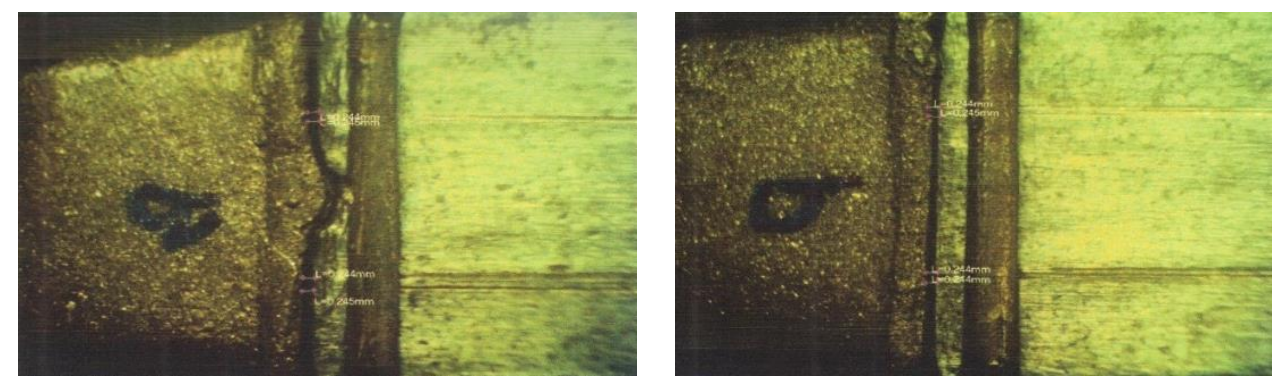

Fig. 7 \& 8: Microscopic view of coping fabricated with accelerated casting technique using metal ring method showing marginal discrepancies (Group 2)
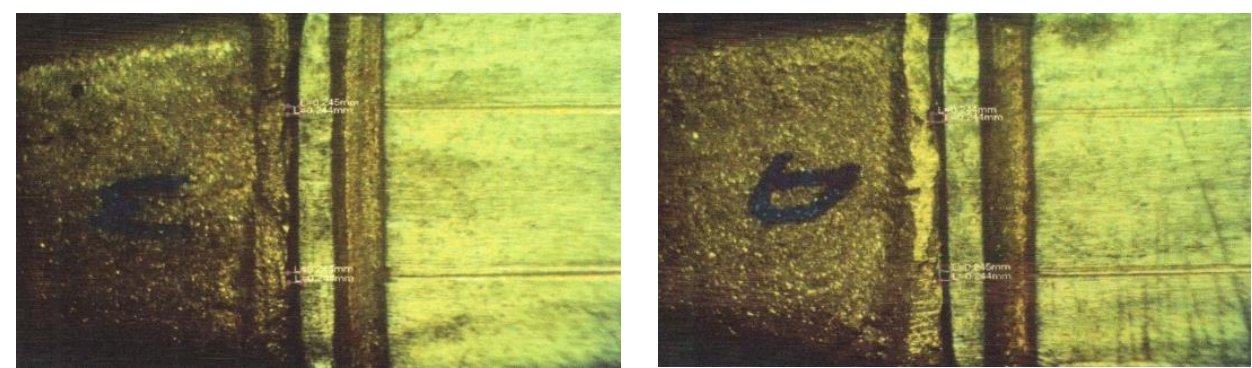

Fig. 9 \& 10: Microscopic view of coping fabricated with conventional casting technique using ringless method showing marginal discrepancies (Group 3)
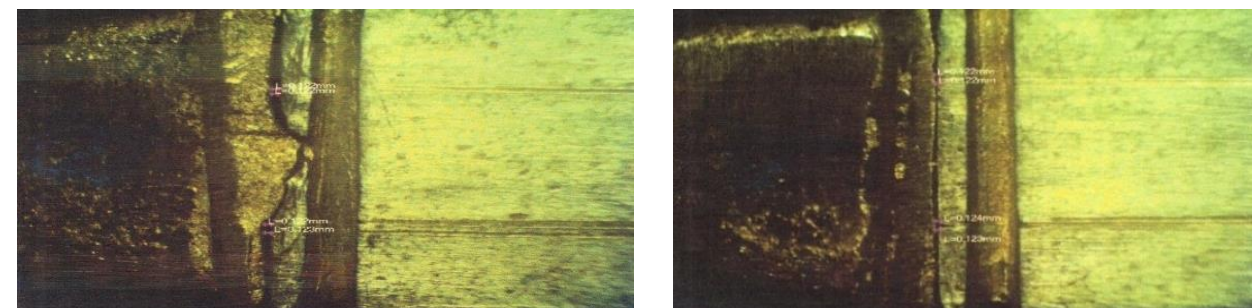

Fig. $11 \&$ 12: Microscopic view of coping fabricated with accelerated casting technique using ringless method showing marginal discrepancies (Group 4) 


\section{Discussion}

The vertical marginal gap of all the 160 copings obtained by four different pattern forming methods showed a statistically significant difference between the four test groups $(\mathrm{G} 4<\mathrm{G} 3<\mathrm{G} 1<\mathrm{G} 2)$. But no statistically significant difference between group I and group II, group I and group III, group II and group III, group II and group IV, and group III and group IV were found.

In the present study, the vertical marginal accuracy of castings fabricated with ring-less system (Group III) was found to be statistically significantly high $(\mathrm{p}<0.001)$. The decreasing order of accuracy of fit of castings among groups was Group III> Group II for conventional casting and Group I > Group IV for accelerated casting. This can be explained on the ground that in the ring-less technique, complete expansion of the mould during setting of the investment occurred uniformly in all directions without any restriction.

In the present study, the vertical marginal accuracy of castings fabricated with conventional technique with ringless method (Group III) was found to be statically highly significant $(\mathrm{p}<0.001)$. The castings fabricated using conventional technique with ringless method showed more consistent type of results compared to restorations fabricated using accelerated technique using ring or ringless method. The result of this study showed that conventional technique using ringless method can be successfully adopted for fabrication of fixed partial denture or implant prosthesis.

\section{Conclusion}

Within the limitation of the study the following conclusions were drawn from the data obtained in this study:

1. Mean Vertical gap was the maximum for Group IV (53.58), followed by Group II (44.27), Group I (44.27) and Group III (36.11), which was statistically significant.

2. Conventional casting using ringless (Group III) coping had shown least vertical marginal discrepancy and statistically significantly better marginal fit than that fabricated by conventional and accelerated casting with metal ring investments.

3. Accelerated casting using ringless (Group IV) coping had shown statistically maximum vertical marginal discrepancy among the four methods. The methods used for accelerated casting technique with using ringless process are technique sensitive. Minor variations in the procedures shown defects such as nodules, fins and porosity.

\section{References}

1. Ana Paula GuminoJainne, Diego kler de et al. effect of cast reflections on the marginal fit of UCLA Abutments $J$ Appl Oral Sci 2007;15(3):169-74.

2. Siadat H. Alikashi M, Mirfazaclian A, Zado MM. Scanning electron microscope evaluation of vertical and horizontal discrepancy in cast copings for single - tooth implant supported prosthesis, Implant Dent 2008;17:299308.

3. Kallus T, BersingC. Loose gold screws frequently occur in full arch fixed prosthesis supported by osseointegrated implants after 5 year. Int J Oral Maxillof Implants 19994;9:169-78

4. Carr AB, Gernd DA, Larsen PE. The response of bone in primates around unloaded dental implants supporting prosthesis with different level of fit. J Prosth Dent 1996;76:500-9

5. Lee A, Okayasu K, Wang HL. Screw- Versus cement retained implant restorations: current concepts. Implant Dent 2010;19:8-15

6. Jent T. Lie A. Accuracy of implant- supported prosthesis in the edentulous jaw. Analysis of precision of fit between cast gold alloy frameworks and master casts by means of a three dimensional photogrammetric technique. Clin oral Implants Res 1995; 6:172-80.

7. Takalashi T. Gunne J. Fit of implant frameworks: an in vitro comparision between two fabrication techniques. $J$ Prosth Dent 2003;89:256-60.

8. Kieth SE, Miller BH, Woody RD, Higginbottom FL.Marginal discrepancy of screw retained and cemented metal ceramic crowns on implants abutments. Int J Oral Maxillof Implants 1999;14;369-78.

9. Bragger U. Karonssis I, Persson R, Pjetursson B, Salis G et al. Technical and biological complication/failures with single crowns and fixed partial dentures on implants. A 10 year prospective cohort study. Clin Oral Implants Res 2005; 16:326-34.

10. Weber HP,Kim DM Ng MW, Hwang JW, Fiorclline JP. Periimplant soft tissue health surrounding cement and screw retained implant restorations. A multicentre, 3 year prospective study. Clinical Oral Implants Research 2006; $17: 375-379$.

11. Wee AG, Aqilino SA, Schneida RL. Strategies to achieve fit in implant prosthodontics: a review of the literature. Int J Prosthod 1999;12:167-78.

12. Jent T Rubenstein JE, Carloson L, Lang BR. Measuring fit at the implant prosthodontic interface $J$ Prosth Dent 1996; 75: 314-25.

13. Sutherland JK, Loney RW, Syed S. Marginal discrepancy of all ceramic crowns cemented on implant abutments $J$ Prostho 1995;4:173-7.

14. HollenbackGM,Shell JS.A further evaluation of the theory of compensation. $J$ South Calif Dent Asso 1965;33:315-7.

15. Morey EF. Dimensional accuracy of gold alloy castings. Part 2.Gold alloy shrinkage. Aust Dent J 1991;36:391 - 6.

16. Morey EF. Dimensional accuracy of gold alloy castings. Part 1. A brief history and the behaviour on inlay waxes. Aust Dent J 1991;36:302-9.

17. Morey EF. Dimensional accuracy of gold alloy castings part3. Gypsum bonded investment expansion. Aust Dent $J$ 1992;37:43-54.

18. Earnshow R. Investments for casting cobalt chromium alloys. Br Dent J 1960;108:389-96,429-40.

19. Matsuya S, Yamane M. Decomposition of gypsum bonded investments J Dent Res 1981;60:1418 -23.

20. Earnshow R. Inlay casting investments. In: 'O' BreinWJ, Ryge G, editions. An Philadelphia; WB Saunders 1978:259-70.

21. EarnshowR.Inlay castings made with ceramic casting ring liners. J Dent Res 1992;71:1865-70.

22. Morey EF, Earnshow R. The fit of gold alloy full crown castings made with pre - wetted casting ring liners. $J$ Dent Res 1992;71:1858-64. 
23. Rudd K, Morrow R, Eissmann H. Dental laboratory procedures. In: fixed partial dentures: investment, burnout and castings. Vol 11l. St Louis: CV Mosby 1981;6:293320.

24. Mc Givney G, Castleberry D. McCracker's removable partial prosthodontics: laboratory procedures St. Loui's: CV Mosby 1989;4:367-426.

25. Deen WM, Himman RW, Hesby RA, Pellen GB Jr. Effect of two step ringless investments technique on alloy castability. J Prosthet Dent 1985;53:874.

26. Carr AB,Stewart RB. Full arch implant framework casting accuracy. Preliminary in vitro observation for in vivo testing. J Prosthodont 1993;2:2-8. 